\title{
An Experiment of Integration of Leprosy Control at the Onset: The Area of Menganti
}

\author{
M. V. J. BLANC, M.D. \\ Saint-Martin-en-Vercours (Drôme) France
}

Among other experiments conducted for the organization of leprosy control in Indonesia was the integration of a mass campaign at the onset of the programme. It started in February 1958 in a selected area of East Java, near Surabaja, which consists of four districts: Drijoredjo, Wriginanom, Menganti and Kedamean, with a total population of I I5,449 inhabitants.

'The reasons for this experiment have been given in another report: 'Integration of leprosy control at the onset of mass campaign in Indonesia.' Here will be given a study of the experiments and its results up to the end of 1962 , that is to say after a period of five years of work.

\section{METHOD AND RESULTS OF CASE-FINDING}

The Centre of the area is the leprosy polyclinic (Out-patient clinic) located at Menganti where there are one leprosy nurse and his assistant nurse. A small building accommodates a waiting room and a treatment room in which all the documents of the leprosy control of the area can be kept. One microscope has been presented and the leprosy nurse is able to examine smears for the detection of leprosy bacilli. The leprosy polyclinic of Menganti is the basis from which all operations are controlled.

The case-finding itself has been organized with the existing djurupateks (assistant yaws workers), one in each of the four districts. All the subdistricts were included in the consolidation phase of yaws campaign.

Two subdistricts: Drijoredjo and Wriginanom, were surveyed during the mass examination of $195^{8}$ and the two others, Menganti and Kedamean, during the year i959. Before starting their survey the djurupateks had been trained during one month and their ability to discover leprosy lesions checked by a leprologist.

As shown in Table I, all 69 villages were examined during the two years, with the effective examination of 99,266 persons out of I I 5,449 inhabitants, that is to say $85.9^{8}$ per cent of the total population. The attendance at this examination was satisfactory.

At the end of the survey (Table II), 73 patients were found in the subdistrict of Drijoredjo ( 3.77 per mille), $6 \mathrm{I}$ in Wriginanom (3.4I per mille), 276 in Menganti ( 7.40 per mille) and I 22 in Kedamean ( $4.9^{2}$ per mille), the average of the whole area, calculated on the number of persons examined, being 5.35 per mille, which is considered as a rather high prevalence in Indonesia. These results are considered to be accurate because, at the end of the first year, an assessment was made during one 
T A B L I: I

\section{Population of the Area of Menganti}

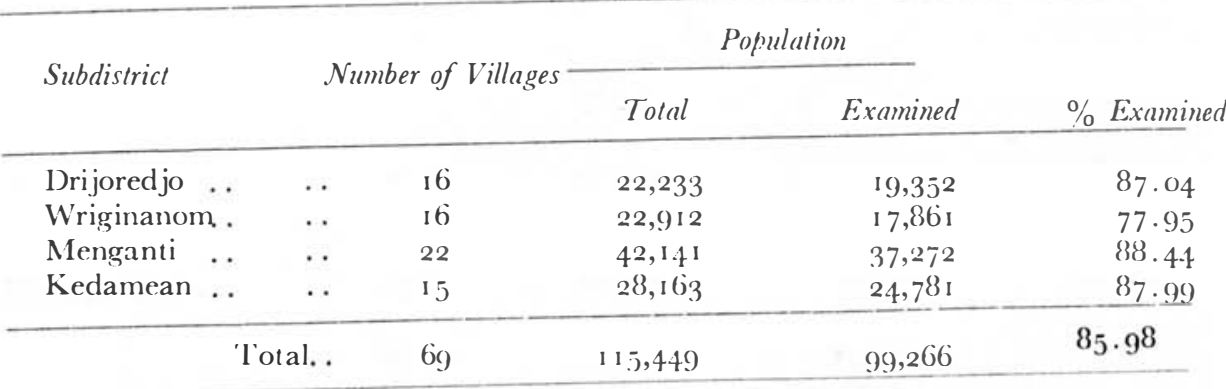

T A B I.E 11

\section{Patients found in each Subdistrict by Mass Survey (1958-1959)}

\begin{tabular}{|c|c|c|c|c|c|}
\hline Subdistrict & & & Population examined & Number of palients & Prevalence of mille \\
\hline Drijored jo $\ldots$ & $\ldots$ & . & $19,3 \bar{j}^{2}$ & 73 & $3 \cdot 77$ \\
\hline Wriginanom.. & . & $\cdots$ & 17,861 & $6 I$ & $34 \mathrm{I}$ \\
\hline Menganti .. & . & . & 37,272 & 276 & 740 \\
\hline Kedamean .. & $\cdots$ & . & $24,78_{1}$ & 122 & $49^{2}$ \\
\hline & tal & . & 99,266 & 5.32 & 535 \\
\hline
\end{tabular}

TABLE III

Sex Distribution of Leprosy Patients

\begin{tabular}{|c|c|c|c|c|c|c|c|}
\hline \multicolumn{5}{|l|}{ Subdistricl } & \multirow{2}{*}{$\begin{array}{c}\text { Male Patients } \\
44\end{array}$} & \multirow{2}{*}{$\frac{\text { Female Patients }}{29}$} & \multirow{2}{*}{$\frac{\text { Ratio }}{\mathrm{I} \cdot 5^{\mathrm{I}}}$} \\
\hline Jrijoredjo & . & . & . & . & & & \\
\hline Wriginanom & . & $\ldots$ & . & . & 40 & 21 & I.90 \\
\hline Menganti & . & . & .. & $\cdots$ & I 99 & 77 & $2 \cdot 5^{8}$ \\
\hline Kedamean & . & $\cdots$ & $\cdots$ & $\cdots$ & $8 \mathrm{I}$ & $4^{1}$ & I. .97 \\
\hline & Total & $\ldots$ & .. & . & 364 & 168 & 2. 16 \\
\hline
\end{tabular}

month in four villages, where 96.5 per cent of the total population was examined by a team of specialized nurses and all cases checked by a team of doctors (dermatologists, leprologist and Public Health Officers) which proved that, even if there was a little overdiagnosis 35 instead of 24 true cases), no case of leprosy was missed. In addition, during the next three years, by repeated spot checking and partial surveys, only 22 new cases were found, all of the Tuberculoid form or early lesions. 
Table III gives the sex distribution of leprosy patients, which conforms to the accepted idea that the discase is more common among men than among women: 2.16 men for one woman.

The age-group distribution, in Table IV, shows two peaks for the agegroup $\mathrm{IO}^{-1} 4$ and that of $25^{-29}$. The majority of patients are included in the groups $10-40$.

The distribution of patients by forms of leprosy (Table V) is interesting: it shows that the number of Indeterminate cases is small (12.40 per cent of the total number of patients), that of 'Tuberculoid cases (resistant form) is high (7I.24 per cent) and that of I.epromatous cases (infectious form) is not too important (I6.36 per cent). Another calculation (Table VI), made to demonstrate the prevalence of each form of leprosy on the number of persons examined, shows that the Lepromatous rate is lower than one

I A IB I E I V

\section{Distribution of Leprosy Patients by Age Groups}

\begin{tabular}{|c|c|c|c|c|c|c|}
\hline Age groups $I$ & Drijoredjo & Wriginanom & Menganti & Kedamean & Total & Percentage \\
\hline$o-4$ & 4 & 2 & 3 & 2 & II & 2.06 \\
\hline $5-9$ & 7 & 2 & 18 & 8 & 35 & 6.57 \\
\hline IO - I 4 & IO & 2 & 49 & I 3 & 74 & I 3.90 \\
\hline $15-19$ & 8 & 5 & $4^{I}$ & 8 & 62 & I I. 65 \\
\hline $20-24$ & 5 & 5 & 22 & 19 & $5^{I}$ & $9 \cdot 5^{8}$ \\
\hline $25-29$ & I 2 & 7 & 33 & $2 \mathrm{I}$ & 73 & I $3 \cdot 72$ \\
\hline $30-34$ & 7 & I I & 28 & I 2 & $5^{8}$ & I 0.90 \\
\hline $35-39$ & 5 & 6 & 30 & I 4 & 55 & I 0.33 \\
\hline $40-44$ & 7 & 5 & I 7 & I I & 40 & $7 \cdot 5^{1}$ \\
\hline $45-49$ & 3 & 9 & 20 & 6 & $3^{8}$ & 7.14 \\
\hline $5^{0}-54$ & 4 & 3 & 8 & 7 & 22 & 4. I 3 \\
\hline $55-59$ & o & 3 & 4 & o & 7 & I $\cdot 3^{I}$ \\
\hline 60 and over & I & I & 3 & 1 & 6 & I. I 2 \\
\hline 'Total & 73 & $6 \mathrm{I}$ & 276 & I 22 & 532 & $99 \cdot 9^{2}$ \\
\hline
\end{tabular}

TABLE V

Distribution of Patients by Forms of Leprosy

\begin{tabular}{|c|c|c|c|c|c|c|}
\hline \multirow{2}{*}{$\begin{array}{l}\text { Forms of } \\
\text { Leprosy }\end{array}$} & \multicolumn{2}{|c|}{ Children } & \multicolumn{2}{|c|}{ Adults } & \multicolumn{2}{|c|}{ All Patients } \\
\hline & Number & Percentage & Number & Percentage & Number & Percentage \\
\hline Indeterminate & 34 & 28.33 & 32 & $7 \cdot 76$ & 66 & I 2.40 \\
\hline 'Tuberculoid & 76 & $63 \cdot 33$ & 303 & $73 \cdot 54$ & 379 & 71.24 \\
\hline Lepromatous & IO & 8.34 & 77 & 18.70 & 87 & I 6.36 \\
\hline Total & 120 & I 00. & 412 & IOO. & 532 & I 00. \\
\hline
\end{tabular}


T A B I, E VI

\section{Prevalence of Leprosy by Forms and by Subdistricts}

(Cialculated, per mille, on the number of persons examined)

\begin{tabular}{|c|c|c|c|c|c|c|}
\hline \multirow{2}{*}{ Subdistrict } & \multicolumn{2}{|c|}{ Indeterminale } & \multicolumn{2}{|c|}{ Tuberculoid } & \multicolumn{2}{|c|}{ Lepromatous } \\
\hline & Number & Prevalence & Number & Prevalence & Number & Prevalence \\
\hline I)rijoredjo & I 6 & 0.82 & $4^{8}$ & $2.4^{8}$ & 9 & $0.4^{6}$ \\
\hline Wriginanom & I0) & 0.55 & 48 & 2.68 & 3 & 0.16 \\
\hline Menganti & 29 & 0.77 & I 94 & 5.20 & 53 & I. 42 \\
\hline Kedamean & I I & 0.44 & 89 & $3 \cdot 59$ & 22 & 0.88 \\
\hline T'otal & 66 & o. 66 & 379 & 3.81 & 87 & 0.87 \\
\hline
\end{tabular}

T A B L E VII

\section{Follow-up of the Area of Menganti from $195^{8}$ to 1963}

I.-Number of Registered patients at the end of 1962 :

\begin{tabular}{|c|c|c|c|c|c|c|c|c|}
\hline & & & & $I$ & $T$ & & $L$ & Total \\
\hline \multirow{2}{*}{\multicolumn{3}{|c|}{$\begin{array}{l}\text { Found during the mass survey } \\
\text { Found during the years } 1960-1962\end{array}$}} & \multicolumn{2}{|r|}{66} & 379 & & 87 & 532 \\
\hline & & & \multicolumn{2}{|r|}{ o } & 22 & & o & 22 \\
\hline \multicolumn{3}{|c|}{ Total } & \multicolumn{2}{|r|}{66} & 401 & & 87 & 554 \\
\hline \multicolumn{3}{|c|}{ Percentage } & \multicolumn{2}{|r|}{ I I.9 } & \multicolumn{2}{|l|}{$72 \cdot 3$} & 15.8 & I OO \\
\hline \multicolumn{9}{|c|}{ 2.-Follow-up of patients during the years $195^{8-1962:}$} \\
\hline & \multicolumn{2}{|c|}{ Indeterminate } & \multicolumn{2}{|c|}{ Tuberculoid } & \multicolumn{2}{|c|}{ Lepromatous } & \multicolumn{2}{|c|}{ All Patients } \\
\hline & Number & $\%$ & Number & $\%$ & Number & $\%$ & Number & $\%$ \\
\hline Dead & I & $\mathrm{I} \cdot 5^{\mathrm{I}}$ & 20 & $4 \cdot 9^{8}$ & 6 & 6.89 & 27 & 4.87 \\
\hline Lost sight of & - & - & 8 & I $\cdot 99$ & 6 & 6.89 & I 4 & 2.56 \\
\hline Worse & - & - & I 2 & $2 \cdot 99$ & - & - & 12 & 2.16 \\
\hline Stationery & - & - & I 4 & $3 \cdot 49$ & 2 & 2.29 & I 6 & 2.88 \\
\hline Improved & 8 & 12. I 2 & 122 & 30.42 & 59 & $67.8 \mathrm{I}$ & I 89 & 34 . I I \\
\hline Arrested & I & $\mathrm{I} \cdot 5^{\mathrm{I}}$ & 83 & 20.69 & I I & I 2.68 & 95 & 17.14 \\
\hline Discharged & $5^{6}$ & 84.86 & 142 & $35 \cdot 44$ & 3 & $3 \cdot 44$ & 201 & 36.28 \\
\hline Total & 66 & I 00. & 401 & Ioo. & 87 & IOO. & 554 & Ioo. \\
\hline
\end{tabular}


per mille: 0.87 only for the whole area, one subdistrict only, Menganti, having a higher rate: 1.42 .

All these case-findings were made in the first place by the rough screening carried out by the djurupateks while examining the population for the combined leprosy/yaws campaign. The findings of the djurupateks werc checked by the leprosy nurse in charge of registration who, instead of being obliged to examine nearly I oo,ooo persons, examined less than I, ooo with the same results.

Each checked and recognized leprosy patient had an individual record form filled in by the leprosy nurse at the initial examination. All the records are kept up-to-date by the leprosy nurse and filed in the leprosy polyclinic. 'They have been used for the following evaluation of leprosy control.

\section{METHOD ANI RESULTS OF TREATMENT}

A further step was made into integration for the treatment of leprosy patients. This is not the task of the djurupateks, but the task of all existing facilities of general medicine and public health.

In the area of Menganti there are four general polyclinics for the treatment of yaws and all common diseases of the population. The nurses responsible for these district polyclinics had a training in the treatment of leprosy with the use of injections of DI)S in oil suspension and they were given the necessary equipment. Leprosy patients have appointment for treatment either in one of these polyclinics or, at fixed dates, in their own villages where the nurse visits. Due to the attractiveness of injections the attendance for treatment was very satisfactory: 86 per cent attendance during the years.

A check made during the first quarter of ${ }_{19} 63$ showed the results obtained for the 554 patients registered in the area. They are as follows:

A small number of patients died -27 , that is to say 4.87 per cent less than one per cent per year. A few people were lost sight of -14 , it is to say $2.5^{6}$ per cent.

Among the other people we find - I 2 worsening (2. I6 per cent) and I 6 stationary (2.88 per cent).

Then comes the very interesting group of 485 patients who were either improved - I89 (34.I I per cent) or arrested - 95 (17.14 per cent) or discharged - 20I ( 36.28 per cent). All discharged patients being already arrested, this means that, after five years of case-finding and treatment, more than half $\left(53.4^{2}\right.$ per cent $)$ of patients are out of danger and are not a possible source of contamination. From the Public Health point of view this is of great value. And in addition more than one third of the patients improve, among whom it is reasonable to expect that, within one or two years, a great number will be arrested, giving the hope that a leprosy mass campaign running at a reasonable speed can stop the disease within ten years.

A more detailed study of the results shows that the great majority of Indeterminate cases (84.86 per cent) are discharged within the five years 
and none of them is worsening. 'luberculoid cases show also a great proportion of arrested and discharged - 5.5. I 3 per cent. I.cpromatous cases are more difficult to treat, but, within this rather short period which totals three years of treatment only for 75 of them, there are 14 arrested or discharged ( 16. I 2 per cent) and the great majority improved $(67.8 \mathrm{I}$ per cent). This last result shows that it will be possible to stop the spreading of the disease by the cure of the most infectious cases of leprosy within a reasonable period.

\section{COONCILUSION}

The experiment of an integrated leprosy control programme in the area of Menganti (Indonesia, province of East Java) proved that an efficient case-finding is possible with the use of non specialized para-medical personnel and that treatment given through the existing medical facilities, under the supervision of a specialized nurse, is able to give very good results. This experiment of integration at the onset of a leprosy mass campaign is a successful example of what can be done and achieved in other parts of the country for an effective control of the disease. 